\title{
Opini Member Mengenai Personal Selling Sales Moka Pos dalam Memasarkan Produk
}

\author{
Olga Puspa Novilini*, Riza Hernawati
}

Prodi Ilmu Hubungan Masyarakat, Fakultas Ilmu Komunikasi, Universitas

Islam Bandung, Indonesia

*Olgapuspa@gmail.com,riza@unisba.ac.id

\begin{abstract}
Large companies application cash Moka POS is one of business competitors in the online. Moka POS system is the point of sales. The point of sales arranged to present information business. If a cafe, then output is menu and price. The output of cash application was sent digitally through sms to customers cellular phones. Moka POS through personal selling post, sell their products use of the executive marketers sales which aims to affect consumer to purchase. On Moka POS sometimes frequent mistake by sales or communication on the application cashier online itself. To the Moka POS give to briefing sales. However sales was not able to practice so they cannot give satisfaction for their customers, this can be seen in figure a customer complaint. The purpose of research to know a member opinion about salesmanship sales, negotiating, marketing sales relationship Moka POS heading in markets better for you products. A method of descriptive with the sampling method of who used in research is the total sampling. The sample collection as many as 95 visitors. Based on the research done, shows that a member opinion about salesmanship sales, negotiating, relationship marketing Moka POS heading in markets better for you products sales could be said to be good because any product Moka POS offer will be able to understand, the manner of serving salesmanship sales, negotiating, relationship marketing to consumer good so consumers business operators become a member of the application of these Moka POS.
\end{abstract}

Keywords: Opinion, Personal Selling Sales, Moka POS

Abstrak. Perusahaan besar aplikasi kasir online yaitu Moka POS adalah salah satu pesaing bisnis dalam bidang online. Moka POS merupakan aplikasi sistem Point of Sales. Sistem Point of Sales diatur agar dapat menyajikan informasi usaha. Apabila pada sebuah kafe, maka output-nya adalah daftar menu dan harga. Output dari aplikasi kasir tersebut dikirimkan secara digital melalui SMS ke ponsel pelanggan. Moka POS melalui personal selling, memasarkan produknya menggunakan tenaga pemasar yaitu Sales Executive yang bertujuan untuk mempengaruhi konsumen agar melakukan pembelian. Pada Moka POS terkadang juga sering terjadi kesalahan komunikasi oleh sales ataupun pada aplikasi kasir online itu sendiri. Untuk meminimalis keluhankeluhan tersebut, Moka POS memberikan pembekalan kepada sales. Namun ternyata sales tersebut belum mampu mempraktekannya sehingga mereka tidak dapat memberikan kepuasan bagi pelanggannya, hal ini dapat dilihat pada gambar keluhan pelanggan. Tujuan penelitian untuk mengetahui opini member mengenai salesmanship sales, negotiating, relationship marketing sales Moka POS dalam memasarkan produk. Metode deskriptif dengan sampling yang digunakan dalam penelitian adalah total sampling. Pengambilan sampel sebanyak 95 orang. Berdasarkan hasil penelitian, menunjukkan bahwa opini member mengenai salesmanship sales, negotiating, relationship marketing sales Moka POS dalam memasarkan produk bisa dikatakan baik karena setiap produk Moka POS yang di tawarkan dapat di mengerti, cara melayani salesmanship sales, negotiating, relationship marketing terhadap konsumen baik sehingga konsumen pelaku usaha menjadi member dari aplikasi Moka POS tersebut.

Kata Kunci: Opini, Personal Selling Sales, Moka POS. 


\section{A. Pendahuluan}

Personal selling membutuhkan komunikasi bisnis yang benar, agar dapat membawa pesan dengan baik dan dipahami oleh calon pelanggan. Penggambaran melibatkan dua orang atau lebih dimana penjual tersebut memberikan informasi-informasi tentang suatu produk secara langsung kepada konsumen (face to face) sehingga peluang mendapatkan feedback akan cepat. Pengaruh personal selling sangatlah besar, dengan kata lain personal selling membutuhkan komunikasi persuasif.

Sebagaimana dapat kita lihat dari ringkasan beberapa pendapat dari beberapa ahli mengenai definisi komunikasi persuasif sebagai berikut: (1) Proses komunikasi yang bertujuan mempengaruhi pemikiran dan pendapat orang lain agar menyesuaikan pendapat dan keinginan komunikator; dan (2) Proses komunikasi yang mengajak atau membujuk orang lain dengan tujuan mengubah sikap, keyakinan dan pendapat sesuai keinginan komunikator. Pada definisi ini 'ajakan' atau 'bujukan' adalah tanpa unsur ancaman/ paksaan (Burgon \& Huffner : 2002) Personal Selling merupakan alat yang efektif pada tahap-tahap tertentu dalam proses pembelian, misalnya; pada tahap pembelian, negosiasi, dan tahap penjualan.

Perusahaan besar aplikasi kasir online yaitu Moka POS adalah salah satu pesaing bisnis dalam bidang online. Moka POS merupakan aplikasi sistem Point of Sales. Sistem Point of Sales diatur agar dapat menyajikan informasi usaha. Apabila pada sebuah kafe, maka output-nya adalah daftar menu dan harga. Output dari aplikasi kasir tersebut dikirimkan secara digital melalui SMS ke ponsel pelanggan. Moka POS melalui personal selling, memasarkan produknya menggunakan tenaga pemasar yaitu Sales Executive yang bertujuan untuk mempengaruhi konsumen agar melakukan pembelian. Pada Moka POS terkadang juga sering terjadi kesalahan komunikasi oleh sales ataupun pada aplikasi kasir online itu sendiri. Untuk meminimalis keluhan-keluhan tersebut, Moka POS memberikan pembekalan kepada sales. Namun ternyata sales tersebut belum mampu mempraktekannya sehingga mereka tidak dapat memberikan kepuasan bagi pelanggannya, hal ini dapat dilihat pada gambar keluhan pelanggan.

Dari uraian latar belakang masalah diatas, peneliti mencoba merumuskan masalah yang akan diteliti sebagai berikut: " bagaimana opini member mengenai personal selling sales Moka POS dalam memasarkan produk?". Untuk memperjelas masalah yang akan dibahas dalam penelitian ini, maka identifikasi masalah yang akan diteliti adalah sebagai berikut :

1. Bagaimana opini member mengenai salesmanship sales Moka POS dalam memasarkan produk?

2. Bagaimana opini member mengenai negotiating sales Moka POS dalam memasarkan produk?

3. Bagaimana opini member mengenai relationship marketing sales Moka POS dalam memasarkan produk?

\section{B. Landasan Teori}

Opini

Opini adalah ekspresi sikap dengan melalui jawaban positif untuk informan yang mendukung, jawaban netral dan negatif untuk jawaban yang tidak mendukung, artinya apabila sesorang beropini positif tandanya orang tersebut mendukung, dan apabila seseorang beropini negatif artinya orang tersebut menolak (Nurudin, 2011:52).

\section{Marketing (Pemasaran)}

Konsep bisnis strategis yang bertujuan untuk meraih kepuasan berkelanjutan bagi ketiga stakeholder utama yaitu: pelanggan, orang-orang dalam organisasi itu, serta pemegang saham. Marketing adalah jiwanya, bukan sekedar bagian dari tubuh organisasi. (Kertajaya, $2004: 19)$.

\section{Sales (Penjualan)}

Merupakan kegiatan yang dilakukan oleh penjual dalam menjual barang atau jasa dengan harapan akan memperoleh laba dari adanya transaksi-transaksi tersebut dan penjualan dapat diartikan sebagai pengalihan atau pemindahan hak kepemilikan atas barang atau jasa dari pihak 
penjual ke pembeli (Mulyadi, 2008:202).

\section{Personal Selling (Penjual Perorangan)}

Komunikasi dua arah antara pembeli dan penjual yang bertujuan untuk memengaruhi keputusan pembelian seseorang atau sekelompok orang (Rangkuti, 2010:181).

\section{Aplikasi Kasir Online atau POS (Point of Sales)}

Sistem yang digunakan untuk melakukan transaksi penjualan retail seperti coffeeshop melalui online.

\section{Hasil Penelitian dan Pembahasan}

Akumulasi Hasil Perhitungan Dimensi Approach (Cara bagaimana mendekati konsumen atau pelanggan) Setelah menguraikan jawaban responden mengenai, dimensi Approach (Cara bagaimana mendekati konsumen atau pelanggan), maka untuk menentukan total tanggapan responden tentangdimensi ini dapat dilihat pada tabel berikut ini.

Tabel 1. Dimensi Approach (Cara bagaimana mendekati konsumen atau pelanggan)

\begin{tabular}{|c|c|c|c|c|c|c|}
\hline \multirow{2}{*}{ Item Pernyataan } & \multicolumn{7}{|c|}{ Frekuensi } & \multirow{2}{*}{ Skor Total } \\
\cline { 2 - 6 } & $\mathbf{5}$ & $\mathbf{4}$ & $\mathbf{3}$ & $\mathbf{2}$ & $\mathbf{1}$ & \\
\hline 1 & 22 & 62 & 9 & 2 & 0 & 389 \\
\hline 2 & 20 & 64 & 10 & 1 & 0 & 388 \\
\hline 3 & 17 & 61 & 15 & 2 & 0 & 368 \\
\hline 4 & 19 & 63 & 12 & 1 & 0 & 385 \\
\hline 5 & 16 & 72 & 6 & 1 & 0 & 388 \\
\hline 6 & 15 & 53 & 19 & 8 & 0 & 360 \\
\hline 7 & 21 & 62 & 9 & 3 & 0 & 386 \\
\hline 8 & 22 & 60 & 10 & 3 & 0 & 386 \\
\hline 9 & 22 & 60 & 10 & 3 & 0 & 386 \\
\hline \multicolumn{7}{|l}{ Jumlah Skor Total } \\
\end{tabular}

Untuk mengkategorikan bagaimana gambaran mengenai dimensi Approach (Cara bagaimana mendekati konsumen atau pelanggan), maka penulis membuat pengkategorian dalam garis interval sebagai berikut:

Jarak interval untuk 9 pertanyaan dengan 95 orang responden.

Nilai Indeks Minimum $=$ Skor Minimum $\mathrm{x}$ Jumlah Pertanyaan $\mathrm{x}$ Jumlah Responden

$$
=1 \times 9 \times 95
$$

$$
=855
$$

Nilai Indeks Maksimum $=$ Skor Maksimum $\mathrm{x}$ Jumlah Pertanyaan $\mathrm{x}$ Jumlah Responden

$$
=5 \times 9 \times 95
$$

Interval

$$
\begin{aligned}
& =4275 \\
& =\text { Nilai Indeks Maksimum }- \text { Nilai Indeks Minimum }
\end{aligned}
$$$$
=4275-855
$$

Jarak Interval

$$
\begin{aligned}
& =3420 \\
& =\text { Interval }: \text { Jenjang }(5) \\
& =3420: 5 \\
& =684
\end{aligned}
$$

Dengan jarak interval sebesar 684 pada masing-masing kategori, maka dapat digambarkan pembagian skor total tanggapan responden mengenai dimensi Approach (Cara bagaimana mendekati konsumen atau pelanggan) dalam bentuk garis kontinum sebagai berikut: 


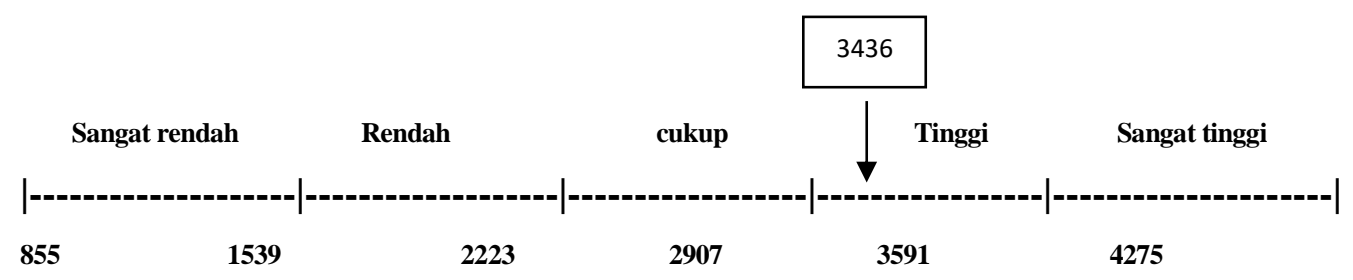

Gambar 1. Garis Kontinum Mengenai Dimensi Approach (Cara bagaimana mendekati konsumen atau pelanggan)

Berdasarkan garis kontinum pada gambar di atas jumlah skor total tanggapan responden tentang dimensi approach (cara bagaimana mendekati konsumen atau pelanggan) diperoleh skor sebesar 3436, dan dalam pengklasifikasian jumlah skor tanggapan responden termasuk dalam kategori tinggi. Berdasarkan pengklasifikasian ini, maka dapat diartikan bahwa apresiasi responden terhadap dimensi approach (cara bagaimana mendekati konsumen atau pelanggan) adalah tinggi.

Akumulasi Hasil Perhitungan Dimensi Handling Objection (Mengatasi klaim konsumen atau pelanggan). Setelah menguraikan jawaban responden mengenai, dimensi Handling Objection (Mengatasi klaim konsumen atau pelanggan), maka untuk menentukan total tanggapan responden tentangdimensi ini dapat dilihat pada tabel berikut ini

Tabel 2. Dimensi Handling Objection (Mengatasi klaim konsumen atau pelanggan),

\begin{tabular}{|c|c|c|c|c|c|c|}
\hline \multirow{2}{*}{ Item Pernyataan } & \multicolumn{7}{|c|}{ Frekuensi } & \multirow{2}{*}{ Skor Total } \\
\cline { 2 - 7 } & $\mathbf{5}$ & $\mathbf{4}$ & $\mathbf{3}$ & $\mathbf{2}$ & $\mathbf{1}$ & \\
\hline 1 & 19 & 58 & 16 & 2 & 0 & 379 \\
\hline 2 & 28 & 51 & 14 & 2 & 0 & 290 \\
\hline 3 & 23 & 62 & 8 & 2 & 0 & 391 \\
\hline 4 & 18 & 57 & 16 & 4 & 0 & 374 \\
\hline \multicolumn{7}{|c}{ Jumlah Skor Total } \\
\hline
\end{tabular}

Untuk mengkategorikan bagaimana gambaran mengenai dimensi Handling Objection (Mengatasi klaim konsumen atau pelanggan), maka penulis membuat pengkategorian dalam garis interval sebagai berikut:

Jarak interval untuk 4 pertanyaan dengan 95 orang responden.

Nilai Indeks Minimum = Skor Minimum x Jumlah Pertanyaan x Jumlah Responden

$$
\begin{aligned}
& =1 \times 4 \times 95 \\
& =380
\end{aligned}
$$

Nilai Indeks Maksimum $=$ Skor Maksimum $\mathrm{x}$ Jumlah Pertanyaan $\mathrm{x}$ Jumlah Responden $=5 \times 4 \times 95$

$$
=1900
$$

Interval

= Nilai Indeks Maksimum - Nilai Indeks Minimum

$=1900-380$

$$
=1520
$$

Jarak Interval

$$
\begin{aligned}
& =\text { Interval }: \text { Jenjang }(5) \\
& =1520: 5 \\
& =304
\end{aligned}
$$

Dengan jarak interval sebesar 304 pada masing-masing kategori, maka dapat digambarkan pembagian skor total tanggapan responden mengenai dimensi Handling Objection (Mengatasi klaim konsumen atau pelanggan) dalam bentuk garis kontinum sebagai berikut: 


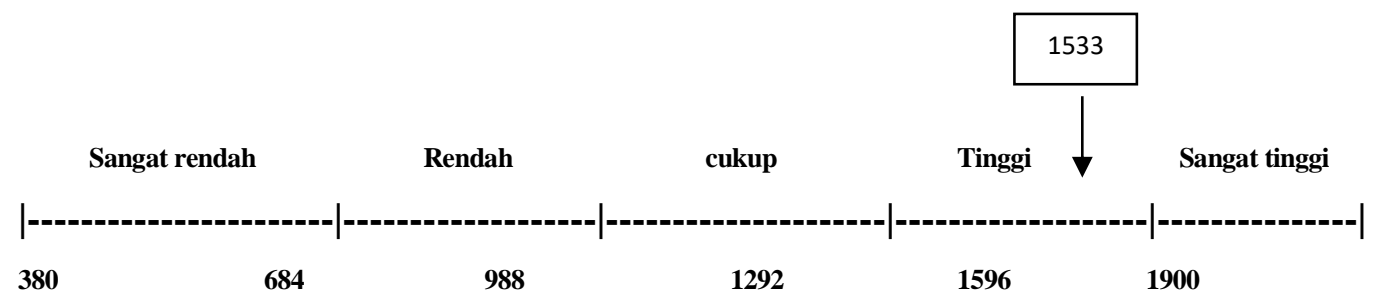

Gambar 2. Garis Kontinum Mengenai Dimensi Handling Objection (Mengatasi klaim konsumen atau pelanggan)

Berdasarkan garis kontinum pada gambar 4.1 jumlah skor total tanggapan responden tentang dimensi Handling Objection (Mengatasi klaim konsumen atau pelanggan) diperoleh skor sebesar 1533, dan dalam pengklasifikasian jumlah skor tanggapan responden termasuk dalam kategori tinggi. Berdasarkan pengklasifikasian ini, maka dapat diartikan bahwa apresiasi responden terhadap dimensi Handling Objection (Mengatasi klaim konsumen atau pelanggan) adalah tinggi.

Akumulasi Hasil Perhitungan Dimensi Presentation and Demonstration (Melakukan presentasi maupun cara meningkatkan penjualan). Setelah menguraikan jawaban responden mengenai, dimensi presentation and Demonstration (Melakukan presentasi maupun cara meningkatkan penjualan), maka untuk menentukan total tanggapan responden dapat dilihat pada tabel berikut ini.

Tabel 3. Presentation and Demonstration (Melakukan presentasi maupun cara meningkatkan penjualan)

\begin{tabular}{|c|c|c|c|c|c|c|}
\hline \multirow{2}{*}{ Item Pernyataan } & \multicolumn{7}{|c|}{ Frekuensi } & \multirow{2}{*}{ Skor Total } \\
\cline { 2 - 6 } & $\mathbf{5}$ & $\mathbf{4}$ & $\mathbf{3}$ & $\mathbf{2}$ & $\mathbf{1}$ & \\
\hline 1 & 22 & 59 & 11 & 3 & 0 & 385 \\
\hline 2 & 10 & 60 & 23 & 2 & 0 & 363 \\
\hline 3 & 12 & 44 & 34 & 5 & 0 & 348 \\
\hline 4 & 13 & 42 & 34 & 6 & 0 & 347 \\
\hline 5 & 13 & 42 & 34 & 6 & 0 & 347 \\
\hline 6 & 22 & 569 & 11 & 3 & 0 & 385 \\
\hline \multicolumn{7}{|c|}{ Jumlah Skor Total } \\
\hline
\end{tabular}

Untuk mengkategorikan bagaimana gambaran mengenai presentation and Demonstration (Melakukan presentasi maupun cara meningkatkan penjualan), maka penulis membuat pengkategorian dalam garis interval sebagai berikut:

Jarak interval untuk 6 pertanyaan dengan 95 orang responden.

Nilai Indeks Minimum = Skor Minimum x Jumlah Pertanyaan x Jumlah Responden

$=1 \times 6 \times 95$

$=570$

Nilai Indeks Maksimum $=$ Skor Maksimum $\mathrm{x}$ Jumlah Pertanyaan $\mathrm{x}$ Jumlah Responden

$=5 \times 6 \times 95$

$=2850$

Interval

= Nilai Indeks Maksimum - Nilai Indeks Minimum

$=2850-570$

$=2280$ 


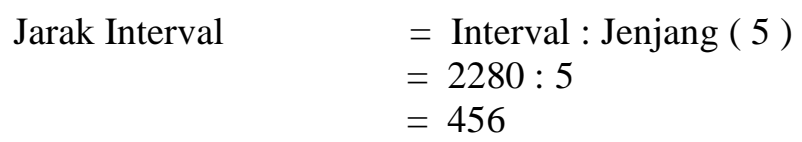

Dengan jarak interval sebesar 456 pada masing-masing kategori, maka dapat digambarkan pembagian skor total tanggapan responden mengenai presentation and demonstration (Melakukan presentasi maupun cara meningkatkan penjualan) dalam bentuk garis kontinum sebagai berikut:

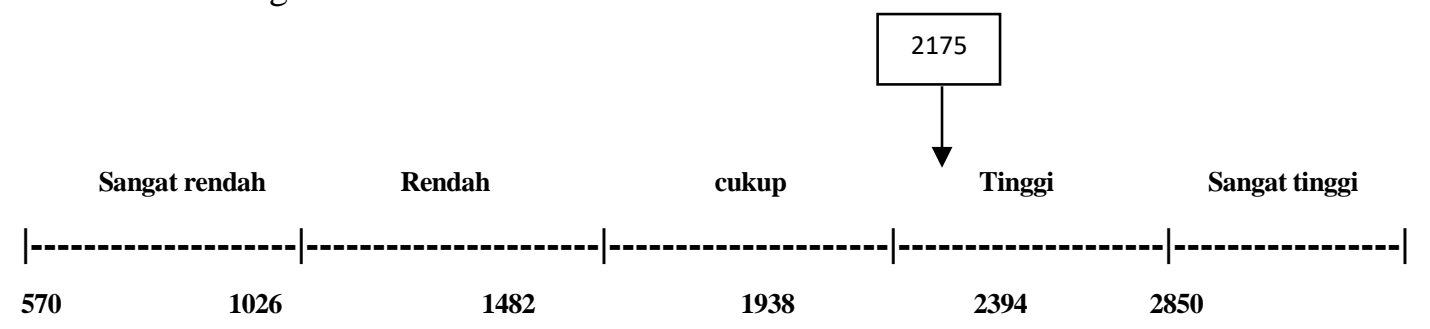

Gambar 3. Garis Kontinum Mengenai Presentation and Demonstration (Melakukan presentasi maupun cara meningkatkan penjualan)

Berdasarkan garis kontinum pada gambar 4.3 jumlah skor total tanggapan responden tentang presentation and Demonstration (Melakukan presentasi maupun cara meningkatkan penjualan) diperoleh skor sebesar 2175, dan dalam pengklasifikasian jumlah skor tanggapan responden termasuk dalam kategori tinggi. Berdasarkan pengklasifikasian ini, maka dapat diartikan bahwa apresiasi responden terhadap presentation and Demonstration (Melakukan presentasi maupun cara meningkatkan penjualan) tinggi.

\section{Kesimpulan}

Dari hasil analisis dan olah data yang dilakukan serta pembahasan yang telah diuraikan pada berdasarkan penelitian yang telah dilakukan terhadap 95 responden mengenai opini member mengenai personal selling sales Moka POS dalam memasarkan produk maka dapat disimpulkan sebagai berikut :

1. Berdasarkan opini member mengenai salesmanship sales Moka POS dalam memasarkan produk dilihat dari aspek approach (Cara bagaimana mendekati konsumen atau pelanggan), personal selling sales Moka POS bisa mendekati calon member dengan baik, karena personal selling sales Moka POS selalu berpenampilan rapih, sopan, dan selalu menjaga penampilan yang mengesankan. Secara handling objection (Mengatasi klaim konsumen atau pelanggan) personal selling sales Moka POS selalu mampu menjawab kebutuhan masyarakat sebagai konsumen yang menjadi target member dalam penggunaan aplikasi Moka POS. Secara presentation and Demonstration (melakukan presentasi maupun cara meningkatkan penjualan) personal selling sales Moka POS selalu siap mempresentasikan aplikasi Moka POS kepada calon member dengan bahasa yang mudah di mengerti oleh para calon member sebagai target marketnya.

2. Berdasarkan opini member mengenai negotiating sales Moka POS dalam memasarkan produk yang diantaranya personal selling sales Moka POS telah berhasil memotivasi konsumen atau pelanggan, personal selling sales Moka POS dapat mengarahkan konsumen menjadi member, serta personal selling sales Moka POS dapat meyakinkan konsumen menjadi member dari aplikasi Moka POS tersebut.

3. Berdasarkan opini member mengenai relationship marketing sales Moka POS dalam memasarkan produk yang diantaranya, interaction customer relationship di mana personal selling sales Moka POS dapat mudah beradaptasi dengan konsumen serta menjalin hubungan dengan baik dengan konsumen sampai menjadi membernya, Coordinating activities di mana personal selling sales Moka POS selalu membangun ikuatan emotional dengan para konsumennya mulai dari membangun komunikasi dan 
lain sebagainya sehingga dengan hal itu dapat menciptakan konsumen menjadi member. Adaptions di mana personal selling sales Moka POS pada saat mempromosikan aplikasi Moka POS ahli dalam beradaptasi dan bisa menyesuaikan diri dari segi waktu bertemu dengan calon konsumennya, sehingga dengan adanya sikap adaptasi personal selling sales Moka POS yang membuat konsumen menjadi member yang diinginkannya.

\section{E. Saran}

\section{Saran Teoritis}

Penelitian ini diharapkan dapat memberikan beberapa hal yang positif bagi ilmu komunikasi, khususnya Public Relations yang meneliti dan mengkaji tentang studi yang berkaitan dengan personal selling seorang sales dalam memasarkan produk dan diharapkan juga mampu menginspirasi penelitian selanjutnya yang berkaitan penelitian yang sama. Hasil penelitian ini diharapkan dapat memberikan gambaran bagaimana kegiatan personal selling dalam memasarkan produknya, mulai dari tahap kegiatan pencarian, presentasi sampai kegiatan penutupan, dan penelitian ini diharapkan dapat memberikan masukan dan peningkatan bagi sales dan perusahaan Moka POS.

\section{Saran Praktis}

1. Penelitian ini diharapkan dapat memberikan pengetahuan dan informasi bagi masyarakat mengenai opini member mengenai personal selling sales Moka POS dalam memasarkan produk. Serta memberikan masukan ataupun inspirasi bagi perusahaan agar lebih meningkatkan strategi dalam menjual produk aplikasi Moka POS yang bermanfaat dan dibutuhkan oleh masyarakat sebagai target konsumennya.

2. Dengan adanya penelitian ini di personal selling sales Moka POS dalam memasarkan produk bisa meningkatkan daya tarik bagi para konsumennya, misalkan selalu berpenampilan rapi, wangi, bersih disesuaikan dengan tujuan baik memakai warna baju, celana, dan sepatu paling tidak harus "matching" atau serasi. Berpakaian formal yang baik untuk member laki-laki dengan mengenakan tidak lebih dari dua warna pakaian, dari atas hingga ujung kaki. Sedangkan untuk member perempuan, pakaian yang nyaman, sopan, dan disesuaikan dengan tempat yang akan dikunjungi.

\section{Daftar Pustaka}

Burgon \& Huffner. 2002. Human Communication. London: Sage Publication.

Mulyadi. 2008. Sistem Akuntansi. Jakarta: Salemba Empat

Mulyana, Deddy. 2011. Ilmu Komunikasi Suatu Pengantar. Bandung: Remaja Rosdakarya.

Kartajaya. Hermawan, 2004. Positioning, Diferensiasi, dan Brand. Jakarta PT. Gramedia Pustaka Utama.

Nurudin, M.Si. 2011. Pengantar Komunikasi Massa. Jakarta : Raja Grafindo Persada.

Rangkuti, Freddy. 2011. SWOT Balanced Scorecard. Jakarta: PT Gramedia. Pustaka Utama. 